\title{
HISTÓRICO DA COLEÇÃO LEOPOLDO GOTUZZO: PROCESSOS DE FORMAÇÃO E CONSTITUIÇÃO
}

\author{
Joana Lizott - Bacharelado em História UFPEL/ MALG \\ joanalizott@gmail.com \\ Orientadora: Prof. Dra. Elisabete da Costa Leal - ICH/UFPEL \\ elisabeteleal@ymail.com
}

\begin{abstract}
RESUMO
A pesquisa aqui apresentada faz parte dos procedimentos de inventário do acervo do Museu de Arte Leopoldo Gotuzzo (MALG), mais especificamente, da Coleção do patrono no museu, o pintor pelotense Leopoldo Gotuzzo (1887-1983). Elaborada como parte de trabalho de conclusão do curso do Bacharelado em História, está vinculada à proposta do Laboratório de Política e Imagem (ICH-UFPEL). Aborda os processos de formação e constituição da coleção Leopoldo Gotuzzo, a partir das formas de aquisição e preservação desse acervo bem como dos mecanismos que levaram a criação do MALG. Assim, a história da formação da coleção pode ser entendida como uma poderosa fonte para questões relativas à criação de memórias e narrativas, para o papel de instituições museológicas, bem como para a história da arte em Pelotas e mesmo nacionalmente.
\end{abstract}

Palavras-chave: Museu; Coleção; Museu de Arte Leopoldo Gotuzzo; Leopoldo Gotuzzo; História da Arte em Pelotas.

\section{INTRODUÇÃO}

A pesquisa aqui apresentada trata-se de parte de um trabalho de conclusão de curso do Bacharelado em História, que apresenta os processos e resultados acerca do inventário da Coleção Leopoldo Gotuzzo. O histórico da coleção foi fundamental para os procedimentos de gerenciamento do acervo, devido a maioria das obras terem sido adquiridas em um período anterior à criação do Museu de Arte Leopoldo Gotuzzo (MALG). 
Conforme as informações eram encontradas, foram sendo revelados contextos diversos que merecem uma discussão mais aprofundada. Assim, esse artigo objetiva apresentar os dados levantados acerca da trajetória da coleção em três momentos, que se referem às instituições que a abrigaram, bem como traçar possíveis desdobramentos dessa pesquisa.

O MALG tem o pintor pelotense Leopoldo Gotuzzo como patrono, com uma coleção formada pelas suas pinturas e desenhos, mas também objetos e documentos de ordem pessoal. Além dessa, possui outras seis coleções ${ }^{1}$, três delas formadas num período anterior à criação do museu. Localizado no centro de Pelotas, o MALG atua com exposições temporárias de seu acervo, além de parcerias com outras instituições, tendo uma sala dedicada às mostras relativas ao patrono do museu. Foi aberto ao público em 1986, e tem seus antecedentes atravessados pela história da coleção Leopoldo Gotuzzo. Isso porque, tanto a instituição quanto o início da coleção possuem fortes vínculos com a Escola de Belas Artes de Pelotas (EBA), da qual Gotuzzo também foi patrono.

O pintor pelotense, segundo Silva e Loreto (1996, p.43-45), é considerado o grande nome da arte pictórica em Pelotas, na primeira metade do século XX. Filho de pai italiano e mãe pelotense, destacou-se pelo desenho desde criança, e iniciou sua formação com o artista Frederico Trebbi, com o qual aprendeu as regras acadêmicas. Continuou os estudos na Europa, de onde volta em 1918 como pintor profissional e premiado. Nos anos 20 viveu a Belle Époque carioca, fixando residência no Rio de Janeiro, sendo esse "O período áureo de sua carreira, incluindo, entre 1927 e 1930, uma viagem a Portugal, expondo em Lisboa, Porto e Paris" (MALG, 1987). Radicou-se no Rio de Janeiro, onde faleceu em 1983.

Fez duas grandes doações de suas obras à Pelotas, uma em 1955 à Escola de Belas Artes e outra quando faleceu, quase trinta anos depois. Além dessas, foram adquiridas obras de outras fontes ao longo dos anos, antes e depois da criação do MALG.

Para a pesquisa foram buscadas as informações nos arquivos da EBA e de Marina de Moraes Pires, bem como em toda documentação de acervo do MALG e do Projeto

\footnotetext{
${ }^{1}$ Coleção Escola de Belas Artes, Coleção Faustino Trápaga, Coleção João Gomes de Mello Filho, Coleção Século XX, Coleção Século XXI e Coleção L.C. Vinholes. Todas passaram pelos mesmos procedimentos de inventário, sendo que atualmente a Coleção L.C. Vinholes está sendo inventariada. Calcula-se que o MALG tenha um total aproximado de 3000 itens em seu acervo.
} 
Pinacoteca - Atelier de Conservação e Restauro dos anos 1980, além de trabalhos acadêmicos acerca da EBA e do Atelier de Restauro da UFPEL.

Inicialmente, trabalhou-se com o agrupamento de toda a documentação referente ao acervo, uma vez que a mesma estava espalhada pelo setor administrativo, de pesquisa e entre os documentos que compõem o arquivo histórico do $\mathrm{MALG}^{2}$. Por documentação referente ao acervo entendeu-se toda e qualquer fonte de informação sobre algum dos itens da coleção. Assim, esses documentos abrangem um período desde 1949 até 2014, ano que começou o trabalho atual. Foram encontradas diversas listagens de quadros, algumas oficiais, como a que relacionava as obras com registro patrimonial da UFPEL, ou informais, como a "Lista de quadros do Museu Leopoldo Gotuzzo", localizada na documentação da EBA. Foram levadas em conta, inclusive, listagens manuscritas e anotações, uma vez que também podiam indicar dados quanto a aquisição dos itens.

Alguns documentos podem ser considerados centrais para a pesquisa, uma vez que, por serem oficiais comprovam de fato a propriedade dos itens. É o caso da já comentada carta de Leopoldo Gotuzzo à Marina de Moraes Pires, o Termo de transferência dos bens da EBA para a UFPEL, o Termo de Responsabilidade quanto ao recebimento de obras doadas pelo pintor em 1983, o Livro Tombo e as Cartas de Doação. Também foram importantes as fichas de identificação do acervo e de restauro, elaboradas por diversos projetos desenvolvidos entorno do acervo ao longo dos anos.

Outras fontes importantes, principalmente quanto ao período inicial da coleção, foram os arquivos da EBA e de Marina Moraes Pires. Esse último é formado por dois conjuntos de documentos organizados em formato de álbuns pela fundadora e diretora da EBA. São recortes de jornal, correspondências, fotografias entre outros, que se referem ao período desde os antecedentes até a federalização da EBA.

O outro conjunto de documentos é da própria EBA, com documentos administrativos, notícias de jornal e muitas fotografias, que fazem parte da Fototeca UFPEL $^{3}$, mas estão sob guarda do MALG. Assim como os arquivos de Marina de Moraes

\footnotetext{
${ }^{2}$ Composto por conjunto de documentos relativos ao Projeto Pinacoteca UFPEL e ao MALG, abrangendo um período de 1982 até 2000. Começou a ser organizado em 2015, pois estava em caixas e pastas em área de depósito do museu. Verificado o conteúdo das mesmas, elas começaram a ser trabalhadas para devido arquivamento.

${ }^{3}$ Disponível on-line em http://www.UFPEL.edu.br/ich/arquivofotografico/>
} 
Pires, os documentos da EBA foram sistematizados e organizados em projetos de extensão e desenvolvimento de mestrado nos anos anteriores, facilitando a pesquisa.

Por fim, também foram utilizados, na busca pela procedência e trajetória da coleção, as dissertações de Clarisse Magalhães (2012), sobre a Escola de Belas Artes de Pelotas e Cláudia Lacerda (2015), sobre o Atelier de Conservação e Restauro do Projeto Pinacoteca, que deu origem ao MALG.

\section{HISTÓRICO DA COLEÇÃO}

Com base nos documentos encontrados, procurou-se pensar na trajetória da coleção a partir de três momentos: as primeiras doações para a Escola de Belas Artes de Pelotas (1949-1973), seguidas das aquisições já no contexto da Universidade Federal de Pelotas, principalmente o legado deixado pelo pintor em 1983, bem como o acervo organizado pelo Projeto Pinacoteca (1982-1985) e por fim, o período após a fundação do MALG, em 1986 até o presente.

\section{Período da Escola de belas artes de pelotas (1949-1973)}

A Coleção Leopoldo Gotuzzo começou a ser formada em 1949, no contexto da Escola de Belas Artes de Pelotas (EBA). Seu marco inicial pode ser considerado a doação da obra "Espanhola", pelo pintor, como agradecimento por ter sido escolhido patrono da escola (Figura 1).

Segundo Clarice Magalhães (2012, p.245), a fundadora e diretora da escola, Marina de Moraes Pires, era bem relacionada com Gotuzzo, com o qual compartilhava o desejo de criar uma instituição voltada para o ensino de artes em Pelotas. Contudo, a pesquisa informa que, mesmo sendo patrono da EBA, a relação de Gotuzzo com a escola se dava à distância, devido sua residência ser no Rio de Janeiro. Assim, ele nunca foi professor da escola. Mesmo assim, visitava a EBA e ministrava pequenas aulas e demonstrações, demonstrando muito apreço pela instituição (MAGALHÃES, 2012, p.245). 


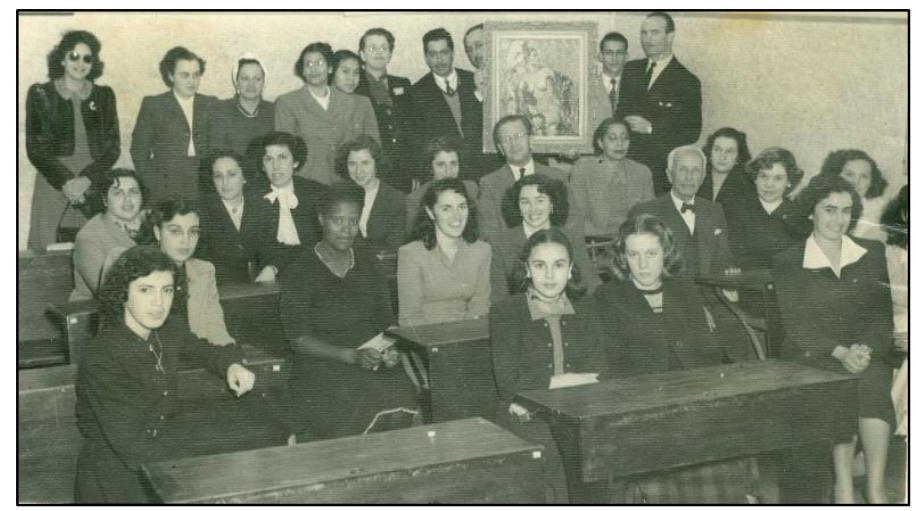

Figura 1: Leopoldo Gotuzzo em meio às alunas da primeira turma da EBA (está sentado à frente da obra entre duas alunas). Ao fundo, proximo ao quadro, identifica-se Marina de Moraes Mires e Aldo Locatelli (direita). Foto de Roble. Fonte: Arquivo Escola de Belas Artes.

O envolvimento com a escola pode ser atestado ainda em 1955, quando Leopoldo Gotuzzo faz uma nova doação de suas obras à EBA. Tal doação é relatada em uma carta enviada à Marina de Moraes Pires ${ }^{4}$, descrevendo o envio de dezesseis obras em nove volumes, cuidadosamente embalados. Segundo Gotuzzo, esses quadros escolhidos representavam a sua carreira artística, e eram doados de forma emocionada, pois ao separar os quadros, repassa boa parte de sua vida, desde o início dos estudos longe da família e do Brasil, até os primeiros prêmios. Finaliza destacando o desejo de que as obras fossem cuidadas e preservadas, como um presente de um pelotense a sua cidade, um testemunho de seu trabalho, desejando "Que Pelotas compreenda e proteja a lembrança de seu filho!" (GOTUZZO, 1955).

Ainda no mesmo ano, verificou-se no Livro de Atas da Diretoria da escola, que outros cinco quadros estariam ainda por vir em doação, estando a espera de "molduras apropriadas", que deveriam ser confeccionadas sob orientação do próprio Gotuzzo (ATA $\mathrm{N}^{\circ}$ 2/955). Não há indicação de quais quadros seriam esses. Essa constatação só foi possível devido o cruzamento de informações entre a "Lista de quadros do Museu Leopoldo Gotuzzo", o Termo de transferência de bens da EBA para a UFPEL e

\footnotetext{
${ }^{4}$ Tal documento encontra-se no MALG, sendo parte da coleção Leopoldo Gotuzzo (inventário 1464/2014).
} 
fotografias da parte interna da EBA, nos quais aparecem obras do pintor não relacionadas na carta de doação direcionada à Marina (Figura 2).

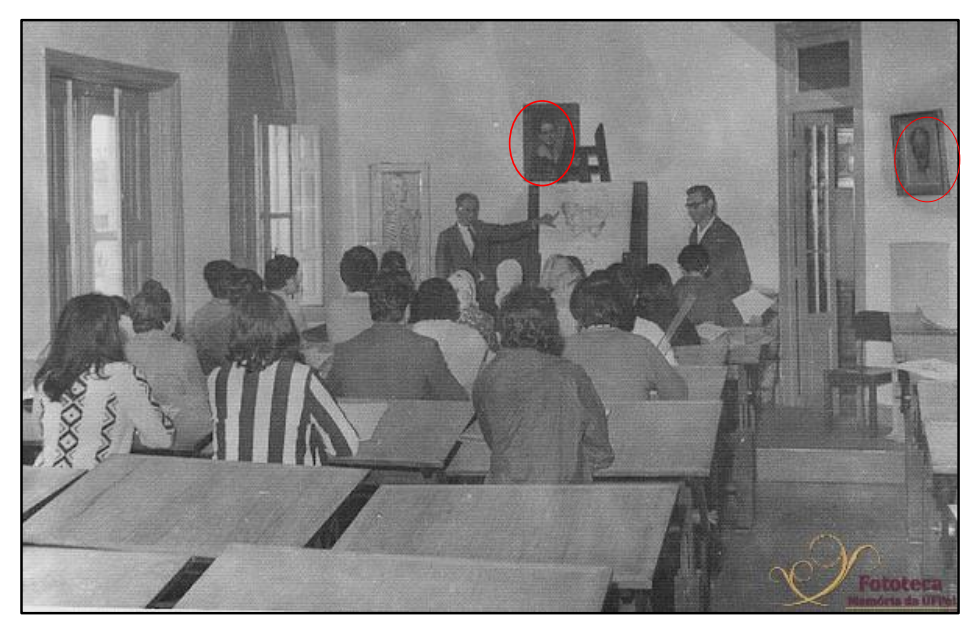

Figura 2: Aula de anatomia na EBA. Nas paredes, dois autorretratos de Leopoldo Gotuzzo, (destacados em vermelho), que hoje fazem parte da Coleção, e podem ser algumas das obras que chegaram depois da doação de 1955. Fonte: Arquivo Escola de Belas Artes/ Fototeca Memória UFPEL.

O período no qual os quadros de Gotuzzo estiveram na EBA é relatado por alguns ex-alunos ${ }^{5}$. O relato de Luciana Renck Reis (2009), é muito elucidativo nesse sentido. Ela foi aluna, professora e posteriormente encabeçou a criação do MALG:

O Gotuzzo sempre dizia que nós, para aprendermos, além de termos que desenhar, estudar e tudo mais, nós tínhamos que ver obras de arte e foi por isso que ele fez a doação das obras dele, mandou a primeira coleção para a Escola. (...) Os quadros do Gotuzzo não estavam em uma só sala, estavam por toda a Escola (...) Mas os quadros do Gotuzzo, provenientes da doação, ficavam lá na Escola, e vocês sabem, tem a poeira, a janela aberta, a luz. Quando o Gotuzzo vinha a Pelotas, ele olhava para ver se os quadros estavam bem. (REIS, 2009)

Assim, percebe-se que as obras eram expostas nas paredes da Escola. Encontrouse ainda, na documentação, referências a um "Museu Leopoldo Gotuzzo", como a Ata 2/55, Lista de quadros e anexo do Termo de Transferência dos bens da EBA para UFPEL Contudo, não foram localizados documentos que comprovem sua institucionalização.

\footnotetext{
${ }^{5}$ Depoimentos constantes no livro: A Escola de Belas Artes de Pelotas: Memória e História, que reúne partes de depoimentos de ex-alunos e professores da escola.
} 
Acredita-se, que esse museu era na verdade a coleção doada por Gotuzzo, não tendo uma estrutura museológica por assim dizer.

Com a criação da Universidade Federal de Pelotas, em 1969, a EBA foi incorporada, com todos os seus bens, em 1972. No ano seguinte, é dado andamento ao processo de transferência da escola, incluindo todas as suas obras de arte, sendo definitivamente incorporada à UFPEL em 1973.

\section{Período UFPEL - Projeto Pinacoteca (1974-1985)}

Depois da incorporação do acervo da Escola de Belas Artes, as obras tiveram destino incerto dentro da UFPEL, tendo ficado espalhadas pelas dependências da instituição "sem manutenção e, muitas delas, em espaços inadequados" (LACERDA, $2015,14)$. Sabe-se pelo registro de entrada patrimonial da universidade, que três obras foram adquiridas pela universidade ainda nos anos 1970, contudo, não se tem a fonte dessas aquisições, nem mesmo a informação se foram doações ou compras.

Somente em 1982, no âmbito do Projeto Pinacoteca, encabeçado pela professora oriunda da EBA Luciana Renck Reis, esse acervo começa a ser tratado novamente em conjunto. O projeto tinha como objetivos a reunião e restauração do acervo artístico espalhado pela universidade, "com a função principal de restauração das pinturas de Gotuzzo, doadas pelo artista à Escola de Belas Artes (EBA) em 1955 e em 1983, para a criação de um futuro Museu" (LACERDA, 2015, 14).

De acordo com reportagem (DIÁRIO POPULAR, 20/01/1983), o ateliê funcionava no prédio da Faculdade de Agronomia Eliseu Maciel, e visava o restauro de 120 quadros (Figura 3). Sob orientação técnica de Elsa Maria Loureiro de Souza ${ }^{6}$, a equipe era coordenada por Luciana Reis e formada pela professora Yedda Machado Luz e escultora Judith Bacci (ambas oriundas da EBA), além de dois estudantes de artes, e o artífice Erasmo Casarin, responsável pelo trabalho em madeira. As pesquisas e fichas do acervo eram de responsabilidade das professoras Vera Satte Alam e Nina Paixão. Ainda

${ }^{6}$ De acordo com documentos diversos encontrados no MALG, as professoras Luciana e Yeda conheceram prof. Elza Maria Loureiro de Souza durante o III Encontro Sul Riograndense de Museus, em Bagé 1982. 
segundo a reportagem, as técnicas empregadas na restauração estavam "de acordo com os métodos aprovados pela UNESCO, para as galerias, pinacotecas e museus dos Estados Unidos e Europa".

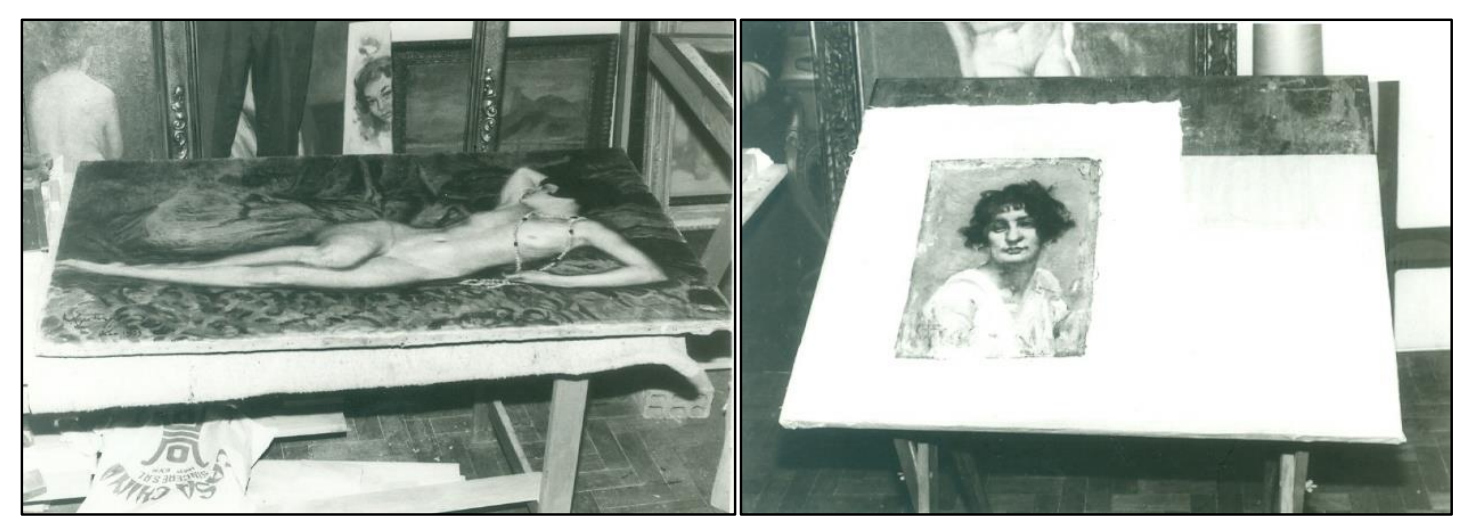

Figura 3: Obras de Gotuzzo em processo de restauro no ateliê do projeto Pinacoteca. Autor não identificado. Fonte: Arquivo do MALG.

Durante essas atividades, segundo depoimento, a professora Luciana Reis, procurou Leopoldo Gotuzzo, então residente do Rio de Janeiro, com a intenção de convidá-lo a ser patrono do novo museu de arte.

Veio a Elza Maria Loureiro de Souza, que tinha feito curso na Europa, então todos os quadros da Escola, não só os do Gotuzzo, ficaram como deveria ser, e eu fiquei muito faceira e fui visitar o Gotuzzo no Rio e disse pra ele: olha, os seus quadros estão perfeitos, maravilhosos. E ele disse: onde é que estão? Eu disse, olha, estão na sala de honra da Universidade. Ele ficou triste e disse assim: sala de honra não é museu. E então eu disse: pois eu vou lhe prometer que o museu sai! (REIS, 2009).

Contudo, Gotuzzo vem a falecer em abril de 1983. É a partir de então que a UFPEL adquire uma quantidade considerável de obras e itens pessoais do pintor. Segundo relatos de servidores, e listagens antigas encontradas, essa aquisição teria sido realizada por meio o testamento do pintor. Infelizmente não se tem acesso ao documento, sendo que a única comprovação oficial da doação é o Termo de Responsabilidade da UFPEL, de 1984, relacionando sessenta (60) itens, a maioria quadros, classificando-os como 
"Doação do autor à Escola de Belas Artes de Pelotas". Como a instituição já não existia, a doação foi direcionada para o Instituto de Letras e Artes da UFPEL (ILA) ${ }^{7}$.

Entretanto, além das obras, foi adquirida no mesmo contexto, uma quantidade significativa de itens de caráter documental, fotográfico e objetos, mas que não foram relacionados ou registrados. A procedência desses itens foi inferida através de listagens manuscritas da época da doação, que indicavam que os mesmos estavam no apartamento de Gotuzzo, em móveis e malas, e tiveram sua doação autorizada pela sua herdeira, Moema Russomano Kraft e o inventariante Jorge Bailly. Outra fonte para determinar quais itens foram adquiridos, é o relatório apresentado pela restauradora Elsa Maria Loureiro, técnica que ficou responsável pela embalagem e envio das obras para Pelotas, uma vez que residia no Rio de Janeiro ${ }^{8}$. Contudo, em nenhum desses documentos a doação é descrita e listada na integra.

Em suma, acredita-se pelas fontes analisadas, que após a morte de Gotuzzo, a restauradora ligada ao projeto Pinacoteca Elza Loureiro, que ficou encarregada de trazer para Pelotas as obras doadas, selecionou também o que estava no apartamento do pintor e conseguiu autorização da herdeira para trazer documentos e objetos. Contudo, apenas os quadros foram formalmente registrados. Assim, essa segunda doação do pintor, teria sido concretizada por sua herdeira Moema Gotuzzo Russomano Kraft, a partir da vontade do pintor ${ }^{9}$.

Além dessa grande doação, o ateliê ainda adquiriu por transferência, após o restauro das mesmas, duas obras de Gotuzzo que pertenciam ao Conservatório de Música de Pelotas ${ }^{10}$. Realizavam exposições do acervo, como a "II Mostra do Acervo Pictórico da UFPEL: ciclo de palestras museologia/acervo pictórico", realizados no Clube Comercial de Pelotas em 1984.

O projeto finaliza em 1985, apontando no seu relatório anual a conclusão do restauro do acervo UFPEL, incluindo a "segunda coleção de Gotuzzo", referindo-se a doação póstuma.

\footnotetext{
${ }^{7}$ Atual Centro de Artes.

${ }^{8}$ Tal relatório encontra-se no arquivo do MALG.

${ }^{9}$ Depoimento oral realizado no MALG em outubro de 2016, com Moema Russomano Gotuzzo Kraft e sua filha Margarida, que confirmaram essas colocações.

${ }^{10}$ Oficio 101/84 de 11/12/1984, de Maria do Carmo Mascarenhas Seus - Diretora Conservatório de Musica para Luciana Reis, coordenadora do projeto Museu Pinacoteca. Arquivo MALG.
} 


\section{Período MALG (1986-atual)}

O MALG abriu ao público em 07 de novembro de 1986. Incorporou quase todo o acervo reunido e restaurado pelo Projeto Pinacoteca, traçando uma linha até a Escola de Belas Artes de Pelotas. A professora Luciana Renck Reis é considerada sua fundadora, e foi a primeira diretora. O Atelier de Restauro iniciado no Projeto Pinacoteca, continuou no museu até o inicio dos anos 1990.

A partir do museu institucionalizado, passam a se somar ao acervo incorporado, obras de arte contemporânea, mas também continuaram a ser adquiridos quadros de Leopoldo Gotuzzo. Em 1993, todas as doações passaram a ser avaliadas previamente por uma comissão.

Já no primeiro ano de funcionamento, em preparação ao centenário de Leopoldo Gotuzzo, o "MALG inicia a conservação e restauro das telas a óleo de Leopoldo Gotuzzo, recebidas pela Universidade Federal de Pelotas dos herdeiros do artista logo após seu falecimento, em cumprimento de vontade expressa em testamento" (DIÁRIO POPULAR, 14/01/1987, p.8).

Ainda nos anos 1990 houve a compra de desenhos do artista por parte da Sociedade de Amigos do MALG (SAMALG) e da reitoria da UFPEL, doados por ambas ao museu.

Por muito tempo, a coleção continuou a ser cuidada pela equipe montada no Projeto Pinacoteca, que se dedicou principalmente ao restauro das obras. Após o fim do ateliê, o acervo ainda ficou sob cuidado de alguns servidores da época, como Erasmo Casarin, que se dedicou intensamente à coleção. Quando ele se aposentou, a função de "guardião" do acervo passou para o servidor que está até hoje no museu, Denoir Oliveira. Ambos não têm formação em gerenciamento ou conservação de acervos, mas atuaram com dedicação, de forma que a coleção, mesmo passando por condições extremas dado edificações inadequadas, mudanças etc, pode ser considerada em muito bom estado.

Durante os anos 1990 e 2000, foram desenvolvidos trabalhos no sentido de se registrar ou pesquisar o acervo. Essas iniciativas podem ser verificadas na documentação levantada para essa pesquisa. Contudo, os vários trabalhos desenvolvidos nem sempre levavam em consideração os anteriores, ou encontram-se incompletos atualmente. Via de 
regra, levavam em conta uma coleção ou um tipo de acervo (como esculturas), não abrangendo a totalidade do acervo do MALG. Mesmo assim, são trabalhos valiosíssimos e demonstram o constante envolvimento e dedicação ao acervo. Todos os resquícios desses trabalhos anteriores foram arquivados recentemente e as informações foram revisadas e incorporadas ao inventário.

$\mathrm{O}$ primeiro trabalho que visava abranger todo o acervo (incluindo todas as coleções e indo além das obras de arte), foi realizado por estagiários do curso de Museologia da UFPEL, orientados pela professora Nóris Leal, entre os anos de 2011 e 2014. O trabalho realizado por eles foi utilizado de base para o inventário atual do acervo.

Assim, ao longo de todos esses anos, a coleção foi se formando, chegando a uma grande variedade de itens, que vão além das obras do artista. Mesmo atualmente, ela não está fechada, sendo adicionadas as novas aquisições relacionadas à Gotuzzo.

\section{CONCLUSÃO}

As informações levantadas sobre a coleção revelam uma trajetória de mais de sessenta anos, passando por diversos processos e lugares, até ser oficialmente criada no contexto museológico.

Dessa trajetória, pode-se perceber como as formas de aquisição, tratamento destinado e até mesmo de comunicação de um acervo são elementos fundamentais para se entender os interesses e processos envolvidos na constituição e no funcionamento dos museus. A coleção Leopoldo Gotuzzo foi formada, com uma intencionalidade, da mesma forma que o museu de arte criado ter sido em sua homenagem não foi ao acaso.

Desde a EBA, na carta enviada à Marina, Gotuzzo já deixa transparecer seu desejo de ser lembrado, e determina como deveria ser essa lembrança, enviando obras que, como o próprio escreve, representavam a sua carreira artística, e eram doados de forma emocionada, pois ao separar os quadros, repassa boa parte de sua vida, desde o início dos estudos longe da família e do Brasil, até os primeiros prêmios. Finaliza destacando o desejo de que as obras fossem cuidadas e preservadas, como um presente de um pelotense a sua cidade, um testemunho de seu trabalho, desejando "Que Pelotas compreenda e proteja a lembrança de seu filho!" (GOTUZZO, 1955). Claramente o pintor declara sua 
vontade de ser lembrado, ao mesmo tempo que esclarece a importância pessoal das obras selecionadas. Essa é uma das principais características dessa doação do pintor à EBA, o fato de ter escolhido, de acordo com suas melhores e mais saudosas experiências, as obras pelas quais queria ser lembrado na sua cidade natal.

A segunda doação já apresenta um contexto mais nebuloso, pela falta do documento definitivo, o testamento do pintor. Contudo, os depoimentos e o projeto Pinacoteca começam a delinear o caminho para a tão esperada criação do museu, ressalto, do museu para Gotuzzo. Nesse aspecto deve-se atentar para o depoimento de Luciana Reis, no qual o pintor não se contenta com uma sala de honra, o restauro e exposição de seus quadros não bastava. Era necessária a institucionalização do processo, a oficialização de seu legado em um museu.

Definida a vontade do artista e seu empenho doando suas obras, fica o questionamento de que processos permitiram que o mesmo alcançasse seu objetivo. $\mathrm{O}$ histórico da coleção aponta algumas pistas, como as pessoas envolvidas e mesmo como o museu foi se constituindo, desde a intenção na EBA, o restauro e exibição no Projeto Pinacoteca até a abertura do MALG e mesmo nos anos seguintes.

Outras questões necessitam de um trabalho mais abrangente, como a representatividade que o trabalho de Gotuzzo tem no contexto artístico local e nacional; se houve uma relação com o privilégio quanto a uma arte mais acadêmica, em detrimento da uma arte contemporânea; qual a intencionalidade e quais foram os grupos envolvidos na preservação dessa coleção e na criação do museu.

Assim, essa pesquisa não se encerra aqui. Tendo servido aos propósitos do inventário da coleção, demanda agora novas abordagens e perspectivas.

\section{REFERÊNCIAS}

LACERDA, Cláudia Fontoura. O Ateliê de Conservação e Restauro da Universidade Federal de Pelotas e suas ações preservacionistas. 2015. Dissertação de mestrado do Programa de Pós-Graduação em Memória e Patrimônio da Universidade Federal de Pelotas.

MAGAlHÃES, Clarice Rego. A Escola de Belas Artes de Pelotas (1949-1973): Trajetória Institucional e papel na História da Arte. 2012. Tese de doutorado do Programa de Pós-Graduação em Educação, da Universidade Federal de Pelotas. 
REIS, Luciana Renck. Depoimento publicado em: SANTO, Anaizi Cruz do Espírito; MAGALHÃES, Clarice Rego. A Escola de Belas Artes: Relatos de Memória. In.: A Escola de Belas Artes de Pelotas - Memória e História. Pelotas: Ed. UFPEL, 2014

SILVA, Úrsula Rosa da, LORETO, Mari Lúcie da Silva. História da arte em Pelotas: a pintura de 1870 a 1980. Pelotas: EDUCAT, 1996.

REIS, Luciana Renck. Depoimento publicado em: SANTO, Anaizi Cruz do Espírito; MAGALHÃES, Clarice Rego. A Escola de Belas Artes: Relatos de Memória. In.: A Escola de Belas Artes de Pelotas - Memória e História. Pelotas: Ed. UFPEL, 2014.

O MALG inicia restauro das telas a óleo de Gotuzzo. Diário Popular, Pelotas, 14 de janeiro de 1987.

Se todos os caminhos levam à Roma, todos também nos levam ao Campus da UFPel. Diário Popular, Pelotas, 20 de janeiro de 1983. 